\title{
DISCRIMINATION OF SEXUAL DIMORPHISM THROUGH EXTERNAL MORPHOLOGY OF SPOTTED STEED (HEMIBARBUS MACULATUS) IN THE YUANHE RIVER, CHINA
}

\author{
TUO, Y. $.^{1,2}-$ XIAO, T. $.^{*}-$ WANG, H. $^{1}$ \\ ${ }^{1}$ Hunan Engineering Technology Research Center of Featured Aquatic Resources Utilization, \\ Hunan Agricultural University, Changsha 410128, China \\ ${ }^{2}$ College of Life Science and Resources Environment, Yichun University, Yichun 336000, China \\ ${ }^{*}$ Corresponding author \\ e-mail: tyxiao1128@163.com; phone:+86-1397-3195-105
}

(Received $27^{\text {th }}$ Sep 2019; accepted $4^{\text {th }}$ Dec 2019)

\begin{abstract}
Sex identification and composition analysis is an important research topic in fish population ecology, and the results have important implications concerning the conservation of wild fish resources and artificial propagation. However, since the individual morphological differences between male and female spotted steed (Hemibarbus maculates) are not obvious, it is usually difficult to identify sex by direct observation. Thus, it is usually done by observing the reproductive system after dissection. However, this method results in the death of the identified fish and cannot be used for later reproduction. To establish a method for sex identification of $H$. maculates by morphological quantitative indicators, 36 directly measured traits and 35 standardized traits from $68 \mathrm{H}$. maculates individuals collected from the Yuanzhou section of the Yuanhe River, China, were measured and analyzed. Based on the data, 13 personalities were screened from the 35 standardized traits by stepwise discriminant method and used to establish discriminant equations. The rate of correctly identifying the male and female individuals was $92.65 \%$. In addition, the condition factor, $D_{7-9}$, the dorsal fin long-throned length, the post-orbital length, $D_{7-10}$, the head length, and the body length were significantly different between male and female $H$. maculates (t-test, $P<0.05$ ). These results implied that the male and female individuals of $H$. maculates could be identified using our established discriminant equations.
\end{abstract}

Keywords: aquaculture, artificial propagation, fish, multivariate analysis, morphological discrimination

\section{Introduction}

Sex identification and composition analysis is an important research content in fish population ecology, and the results have important guidance to conservation of wild fish resources and artificial propagation (Chang et al., 2015; Lombardi-Carlson and Andrews, 2015; An et al., 2017). Sex can be distinguished by the differences of body size and secondary sexual characteristics for fish with obvious heteromorphism. However, it is very hard to distinguish the sex for fish that do not have obvious heteromorphism, such as Acrossocheilus wenchowensis (Xu et al., 2006), Khanka spiny bitterling (Acanthorhodeus chankaensi Dybowsky) (Chen et al., 2013a), and top-mouth culter (Eryghroculter ilishaeformis) (Chen et al., 2013b). There are a lot of limitations in the use of anatomical and other sex identification methods, which are not conducive to the protection of studied fish and the implementation of artificial reproduction. Methods that identify male and female individuals by quantitative indicators of body shape characteristics has been successfully applied in many fish, such as elongate ilisha (Ilisha elongata) (Ni and Chen, 2003), Japanese eel (Aniguilla japonica) (Guo et al., 2011) and spotted scat (Scatophagus argus) (Wu et al., 2014). Though the application of 
discriminant equation that is established according to fish morphological indexes, the accuracy of sex identification can be as high as $85 \%$.

Spotted steed (Hemibarbus maculatus Bleeker) is a small freshwater Cyprinidae fish, which is an endemic fish in China. Morphology and population ecology of H. maculatus living in different rivers have been studied (Wu et al., 1979; Miao and Yin, 1983; Xie et al., 1988; Fu and Qiao, 2008; Li et al., 2012; Tuo, 2012, 2013; Sun et al., 2014). Lin et al. (2005) report that there is no significant difference in individual size between male and female $H$. maculatus in the Oujiang River. Our previous investigation to H. maculatus in the Ganjiang River also shows that there is no obvious difference in individual size between male and female individuals of wild $H$. maculatus. Sexual maturity of male and female H. maculatus is not synchronous. Generally, the male fish reach sexual maturity in March, while the female fish reach sexual maturity in April or May. The parasexual characteristics of mature male fish lasted for a short time, and were obvious in March, but not in April and May. In addition, the abdominal bulge of the male fish is similar to that of females due to a large amount of food intake. Therefore, sex of $H$. maculatus cannot be identified directly from its morphological characteristics, which is not conducive to carrying out population ecology investigation and artificial reproduction. Therefore, to solve the problem of sex identification and provide reference for the study of population ecology and artificial reproduction of $H$. maculatus, in the present study, we systematically analyzed the morphological indexes of $H$. maculatus in the Ganjiang River, and established a sex identification model of $H$. maculatus.

\section{Materials and Methods}

\section{Sample collection}

H. maculatus samples were collected from the Yuanzhou section of the Yuanhe River using screen meshes and floor cages from December 2010 to June 2012 (113 $54^{\prime}-114^{\circ} 37^{\prime}$ E, $27^{\circ} 33^{\prime}-28^{\circ} 05^{\prime} \mathrm{N}$; Fig. 1). The Yuanhe River is a breach of the Ganjiang River. Fresh samples were placed in containers with oxygen pump, which can continuously oxygenate, and were quickly transport to the laboratory. The fish samples were anaesthetized using anesthetic MS-222 (50 mg/L) for 3-5 min before morphological measure and dissecting for sex identification. All experiments were carried out in accordance with the Animal Ethics Committee of Hunan Agricultural University.

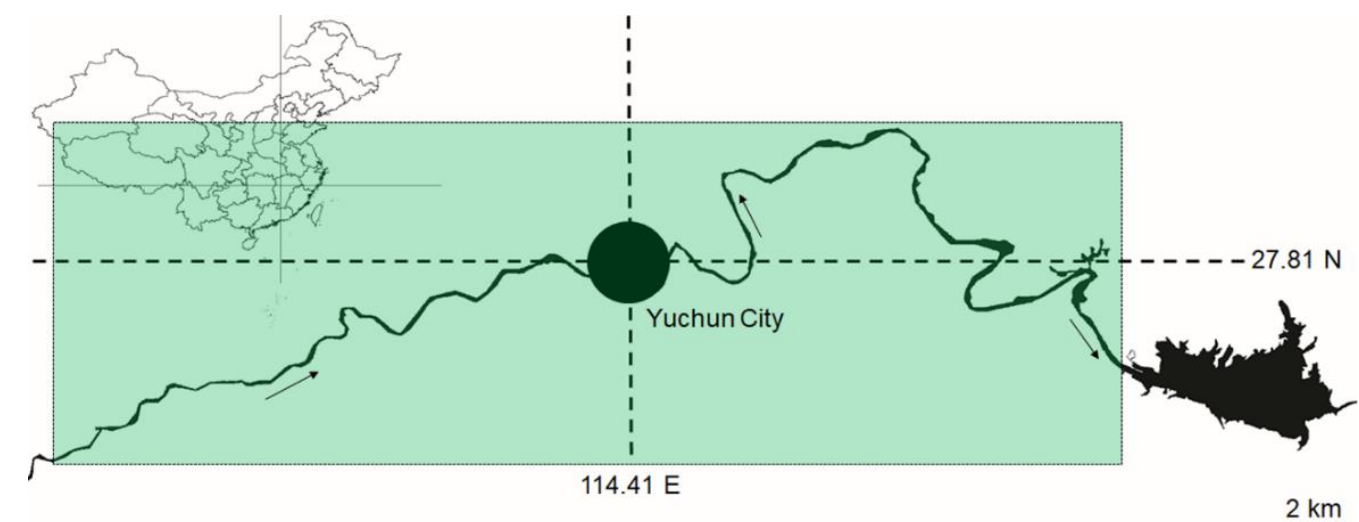

Figure 1. Map shows sampling area. The green rectangular area shows the range of sampling section of the river. The black arrows indicate the direction of water flow 


\section{Measurement of morphological indicators}

Body length $(B L)$, head length $(H L)$, head width $(H W)$, head height $(H H)$, snout length $(S L)$, post-orbital length $(P L)$, eye diameter $(E D)$, interorbital width $(I W)$, mouth width $(M W)$, mouth length $(M L)$, body highness $(B H)$, pectoral fin length $(P F L)$, Caudal fin length $(C F L)$, distance between pelvic fin and anal fin $(P A F D)$, and dorsal fin longthroned length $(D F L)$ were measured using rulers and vernier calipers according to previous description (Fish Research Laboratory of Hubei Institute of Hydrobiology, 1976; Lin et al., 2005). The lengths were accurate to two decimal places. Sex glands were dissected and sex was identified by naked eyes. Fish body weight $(W)$, gonad weight $\left(W_{g}\right)$, and shell weight $\left(W_{0}\right)$ were weighed by an electronic balance. The weights were accurate to two decimal places. The condition factor $(K)$ was calculated as follows,

$$
K=100 \times\left(W / B L^{3}\right)
$$

where $W$ was body weight, and $B L$ was body length.

Ten coordinate points were set up on the surface of fish based on the truss network theory (Fig. 2A), according to previous reports (Strauss and Bookstein, 1982; Corti et al., 1988; Bookstein, 1997). A total of 21 truss network measurement traits were measured, including $D_{1-2}, \ldots$, and $D_{9-10}$. The measured distance of truss network structure was the straight-line distance between two points (Fig. 2B).

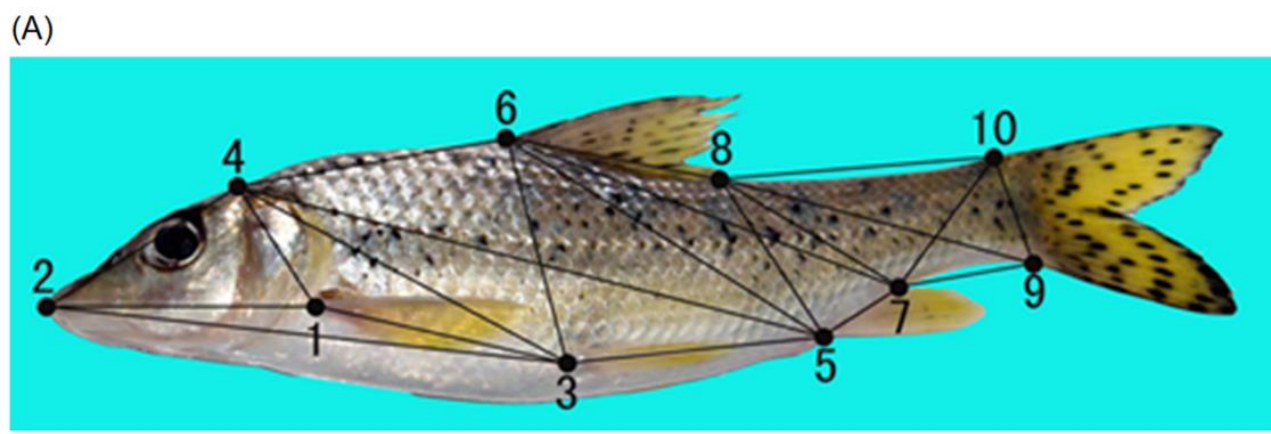

(B)

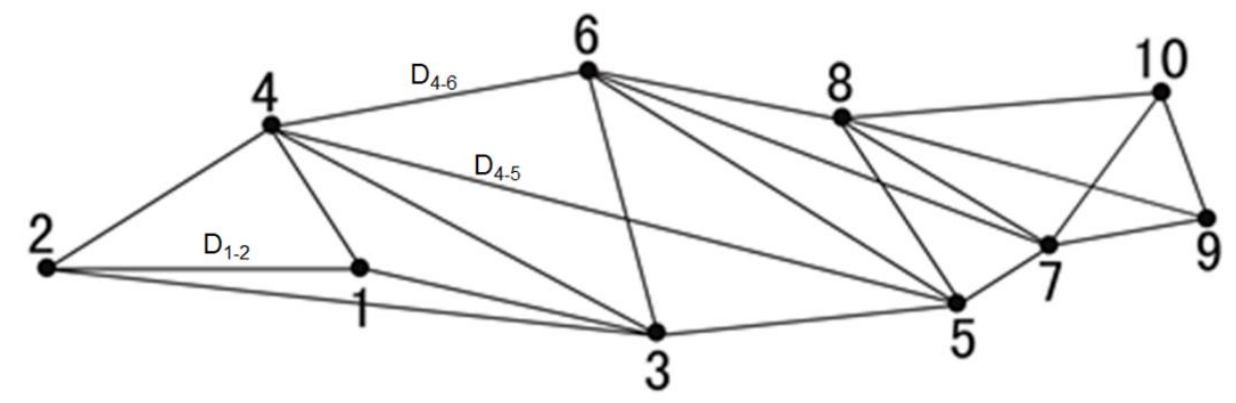

Figure 2. Schematic measuring points based on the truss network (A) and representation examples of the distances between points $(B)$

\section{Data analysis}

Data were recorded using Excel 2003 and analyzed using Statistica 10. Date are expressed as mean \pm standard deviation (S.D.). In the present study, we analyzed three 
types of data, i.e. (1) data from traditional morphological indices, (2) data from truss network indices, and (3) data combing traditional morphological indices with truss network indices. Considering fish size is influenced by the age of fish, we also analyzed the traditional morphological data and truss network indices using three data transformed modes, i.e., ratio:

$$
M_{a d j}=M / S L
$$

logarithmic ratio:

$$
M_{a d j}=\log M / \log S L
$$

and logarithmic heterocorrelation index (ALLOM):

$$
M_{a d j}=\log M-b\left(\log S L-\log S L_{\text {mean }}\right)
$$

according to previous reports (Turan, 1999; Turan et al., 2004; Pinheiro et al., 2005). Where $M$ is the local characteristic measurements of each specimen, $S L$ is the body length of each specimen, $S L_{\text {mean }}$ is the mean body length of male or female fish, and $b$ is the slope of linear regression of $\log _{10} M$ and $\log _{10} S L$.

Index of sexual heteromorphism $\left(I_{s h}\right)$ was calculated as follows (Gibbons and Lovich, 1990; Shou et al., 2005),

$$
I_{\text {sh }}=1-B L_{\text {mean.sbs }} / B L_{\text {mean.lbs }}
$$

where $I_{s h}$ is the index of sexual heteromorphism, $B L_{\text {mean.sbs }}$ is mean body length of the gender with smaller body size, and $B L_{\text {mean.lbs }}$ is mean body length of the gender with larger body size. Student's $t$ test was used to compare the body length and 35 morphological parameters of male and female individuals. The significant level was set to $p=0.05$.

A comprehensive index with the largest eigenvalue vector was selected from 35 directly measured characteristic parameters, and the principal component with a larger contribution rate was determined, then the principal component analysis (PCA) profile was drawn. R-cluster analysis was conducted based on the Pearson correlation coefficient. Stepwise regression method was used to further analyze and screen the characteristics with significant differences between male and female individuals, and the discriminant equations of male and female $H$. maculatus were established.

\section{Results}

\section{Heteromorphism of male and female $\mathrm{H}$. maculatus}

A total of $68 \mathrm{H}$. maculatus samples were collected. The BLs of female $\mathrm{H}$. maculatus were range from 11.00 to $26.90 \mathrm{~cm}(17.88 \pm 3.91 \mathrm{~cm})$, which were larger than those of male $H$. maculatus (range from 11.60 to $21.60 \mathrm{~cm}, 15.82 \pm 3.25 \mathrm{~cm}$; Table 1 ). The $I_{s h}$ was 0.126 . The individual size of male and female $H$. maculatus samples were significantly different (t-test, $t=-2.36, P=0.021$; Table 1 ). The morphological parameters were positively correlated with the body length (Appendix 1). The correlation coefficients were range from 0.278 to 0.903 . After logarithmic heterodyne transformation according to the 
equation $E q .4$, the $D_{7-9}$, and $D_{7-10}$ of males were significantly higher than those of females (t-test, $P<0.05)$. The $K, H L, P L$, and $D F L$ of females were significantly higher than those of males (t-test, $P<0.05$ ). There was no significant difference in other local characteristics between the sexes (Table 1).

Table 1. Descriptive statistics of morphological traits of $H$. maculates $(\mathrm{cm})$

\begin{tabular}{|c|c|c|c|c|c|c|}
\hline \multirow{2}{*}{ Characters } & \multicolumn{2}{|c|}{ Female } & \multicolumn{2}{|c|}{ Male } & \multirow{2}{*}{ t-value } & \multirow{2}{*}{ p-value } \\
\hline & Sampling size & Mean \pm S.D. & Sampling size & Mean \pm S.D. & & \\
\hline BL & 33 & $17.88 \pm 3.91$ & 35 & $15.82 \pm 3.25$ & -2.36 & 0.021 \\
\hline$D_{1-2}$ & 33 & $0.63 \pm 0.03$ & 35 & $0.63 \pm 0.03$ & 0.20 & 0.844 \\
\hline$D_{1-3}$ & 33 & $0.64 \pm 0.05$ & 35 & $0.64 \pm 0.04$ & -0.06 & 0.953 \\
\hline $\mathrm{D}_{2-3}$ & 33 & $0.93 \pm 0.04$ & 35 & $0.93 \pm 0.04$ & -0.07 & 0.944 \\
\hline $\mathrm{D}_{2-4}$ & 33 & $0.56 \pm 0.05$ & 35 & $0.56 \pm 0.05$ & -0.21 & 0.832 \\
\hline $\mathrm{D}_{1-4}$ & 33 & $0.41 \pm 0.06$ & 35 & $0.41 \pm 0.07$ & 0.44 & 0.658 \\
\hline $\mathrm{D}_{3-4}$ & 33 & $0.77 \pm 0.05$ & 35 & $0.78 \pm 0.04$ & 0.69 & 0.490 \\
\hline $\mathrm{D}_{3-5}$ & 33 & $0.63 \pm 0.05$ & 35 & $0.65 \pm 0.07$ & 0.84 & 0.407 \\
\hline $\mathrm{D}_{4-6}$ & 33 & $0.63 \pm 0.05$ & 35 & $0.64 \pm 0.05$ & 1.04 & 0.301 \\
\hline $\mathrm{D}_{3-6}$ & 33 & $0.60 \pm 0.04$ & 35 & $0.58 \pm 0.09$ & -0.91 & 0.369 \\
\hline $\mathrm{D}_{4-5}$ & 33 & $0.99 \pm 0.05$ & 35 & $1.00 \pm 0.03$ & 1.16 & 0.252 \\
\hline D5-6 & 33 & $0.79 \pm 0.04$ & 35 & $0.79 \pm 0.05$ & 0.03 & 0.974 \\
\hline $\mathrm{D}_{5-7}$ & 33 & $0.12 \pm 0.08$ & 35 & $0.11 \pm 0.06$ & -0.31 & 0.758 \\
\hline $\mathrm{D}_{6-8}$ & 33 & $0.35 \pm 0.05$ & 35 & $0.37 \pm 0.04$ & 1.37 & 0.177 \\
\hline D5-8 & 33 & $0.62 \pm 0.05$ & 35 & $0.62 \pm 0.04$ & 0.14 & 0.885 \\
\hline$D_{6-7}$ & 33 & $0.85 \pm 0.05$ & 35 & $0.84 \pm 0.04$ & -0.03 & 0.977 \\
\hline $\mathrm{D}_{7-8}$ & 33 & $0.69 \pm 0.05$ & 35 & $0.69 \pm 0.04$ & -0.09 & 0.928 \\
\hline $\mathrm{D}_{7-9}$ & 33 & $0.36 \pm 0.08$ & 35 & $0.40 \pm 0.05$ & 2.77 & 0.008 \\
\hline$D_{8-10}$ & 33 & $0.82 \pm 0.04$ & 35 & $0.83 \pm 0.03$ & 1.60 & 0.116 \\
\hline $\mathrm{D}_{8-9}$ & 33 & $0.85 \pm 0.06$ & 35 & $0.85 \pm 0.06$ & 0.18 & 0.885 \\
\hline$D_{7-10}$ & 33 & $0.47 \pm 0.05$ & 35 & $0.49 \pm 0.04$ & 2.02 & 0.048 \\
\hline $\mathrm{D}_{9-10}$ & 33 & $0.25 \pm 0.04$ & 35 & $0.26 \pm 0.03$ & 0.83 & 0.412 \\
\hline HL & 33 & $0.64 \pm 0.02$ & 35 & $0.63 \pm 0.03$ & -2.51 & 0.015 \\
\hline PL & 33 & $0.23 \pm 0.05$ & 35 & $0.21 \pm 0.03$ & -2.92 & 0.005 \\
\hline$D F L$ & 33 & $0.57 \pm 0.03$ & 35 & $0.55 \pm 0.03$ & -2.89 & 0.005 \\
\hline$K$ & 33 & $1.51 \pm 0.31$ & 35 & $1.79 \pm 0.24$ & 4.01 & $<0.001$ \\
\hline $\mathrm{HH}$ & 33 & $0.38 \pm 0.03$ & 35 & $0.38 \pm 0.04$ & -0.30 & 0.762 \\
\hline HW & 33 & $0.35 \pm 0.06$ & 35 & $0.35 \pm 0.07$ & 0.09 & 0.925 \\
\hline SL & 33 & $0.23 \pm 0.18$ & 35 & $0.18 \pm 0.05$ & -1.61 & 0.116 \\
\hline ED & 33 & $0.00 \pm 0.04$ & 35 & $0.00 \pm 0.04$ & 0.30 & 0.768 \\
\hline IW & 33 & $0.18 \pm 0.11$ & 35 & $0.18 \pm 0.07$ & 0.0004 & 1.000 \\
\hline $\mathrm{BH}$ & 33 & $0.55 \pm 0.04$ & 35 & $0.57 \pm 0.04$ & 1.84 & 0.071 \\
\hline ML & 33 & $-0.01 \pm 0.08$ & 35 & $-0.01 \pm 0.05$ & -0.17 & 0.867 \\
\hline PFL & 33 & $0.53 \pm 0.05$ & 35 & $0.51 \pm 0.04$ & -1.47 & 0.148 \\
\hline CFL & 33 & $0.55 \pm 0.05$ & 35 & $0.54 \pm 0.04$ & -1.63 & 0.108 \\
\hline PAFD & 33 & $0.63 \pm 0.04$ & 35 & $0.63 \pm 0.03$ & 0.40 & 0.692 \\
\hline
\end{tabular}

Except BL, other morphological parameters were logarithmically heterodyne transformed. Date are expressed as mean \pm S.D. $(\mathrm{cm})$. Transformation variables are compared with t-test. BL, body length; HL, head length; ED, eye diameter; PL, post-orbital length; DFL, dorsal fin long-throned length; K, condition factor; HH, head height; HW, head width; SL, snout length; IW, interorbital width; BH, body highness; ML, mouth length; PFL, pectoral fin length; CFL, caudal fin length; PAFD, Distance between pelvic fin and anal fin

\section{Correlations between morphological characteristic variables of $\mathrm{H}$. maculatus}

The first three principal components of 35 morphological characteristics of H. maculatus explained $85.17 \%$ of variation (Table 2 ). $B L, D_{1-2}, D_{1-3}, D_{2-3}, D_{5-6}, D_{9-10}$, $D_{4-6}, D_{6-7}$, and $H L$ had higher positive load coefficients in the first principal component (explaining $75.93 \%$ of variation). $K$ had a higher positive load coefficient in the second principal component (explaining $6.40 \%$ of variation). $H L$ had a higher positive load 
coefficient in the third principal component (explaining 2.85\% of variation; Table 2). The morphological features overlapped greatly, and some local features were significantly separated (Fig. 3A).

Table 2. Factor loadings of principal components extracted from 35 morphological characters in male and female $H$. maculatus

\begin{tabular}{|c|c|c|c|}
\hline \multirow{2}{*}{ Character } & \multicolumn{3}{|c|}{ Component } \\
\hline & 1 & 2 & 3 \\
\hline$B L$ & 0.98 & 0.02 & 0.00 \\
\hline$D_{1-2}$ & 0.97 & 0.00 & 0.03 \\
\hline$D_{1-3}$ & 0.95 & 0.05 & -0.03 \\
\hline $\mathrm{D}_{2-3}$ & 0.97 & 0.02 & -0.02 \\
\hline$D_{2-4}$ & 0.92 & 0.03 & -0.01 \\
\hline $\mathrm{D}_{1-4}$ & 0.80 & -0.03 & -0.03 \\
\hline $\mathrm{D}_{3-4}$ & 0.97 & 0.03 & -0.07 \\
\hline $\mathrm{D}_{3-5}$ & 0.82 & -0.07 & 0.02 \\
\hline $\mathrm{D}_{4-6}$ & 0.96 & -0.01 & -0.05 \\
\hline $\mathrm{D}_{3-6}$ & 0.77 & 0.12 & -0.06 \\
\hline $\mathrm{D}_{4-5}$ & 0.98 & -0.02 & 0.01 \\
\hline $\mathrm{D}_{5-6}$ & 0.97 & 0.01 & 0.02 \\
\hline $\mathrm{D}_{5-7}$ & 0.91 & 0.10 & 0.00 \\
\hline D6-8 & 0.95 & -0.02 & -0.01 \\
\hline $\mathrm{D}_{5-8}$ & 0.94 & -0.03 & 0.15 \\
\hline$D_{6-7}$ & 0.96 & 0.04 & 0.01 \\
\hline $\mathrm{D}_{7-8}$ & 0.94 & 0.00 & 0.10 \\
\hline $\mathrm{D}_{7-9}$ & 0.81 & -0.29 & 0.16 \\
\hline $\mathrm{D}_{8-10}$ & 0.96 & -0.10 & 0.09 \\
\hline $\mathrm{D}_{8-9}$ & 0.86 & -0.03 & 0.14 \\
\hline$D_{7-10}$ & 0.90 & -0.19 & 0.08 \\
\hline$D_{9-10}$ & 0.96 & -0.05 & 0.02 \\
\hline$H L$ & 0.97 & -0.05 & -0.05 \\
\hline$H H$ & 0.94 & 0.00 & -0.04 \\
\hline$H W$ & 0.88 & 0.11 & -0.27 \\
\hline$S L$ & 0.27 & -0.35 & 0.76 \\
\hline$P L$ & 0.95 & -0.08 & -0.02 \\
\hline$E D$ & 0.78 & 0.01 & -0.20 \\
\hline$I W$ & 0.86 & 0.08 & -0.10 \\
\hline$M L$ & 0.92 & 0.08 & -0.01 \\
\hline$B H$ & 0.93 & 0.14 & -0.04 \\
\hline$P F L$ & 0.92 & -0.11 & -0.13 \\
\hline$C F L$ & 0.91 & -0.13 & -0.04 \\
\hline$P A F D$ & 0.92 & 0.02 & -0.02 \\
\hline$D F L$ & 0.92 & -0.12 & -0.03 \\
\hline K & 0.06 & 0.69 & -0.23 \\
\hline Eigenvalues & 28.85 & 2.43 & 1.08 \\
\hline Contribution rate $(\%)$ & 75.93 & 6.40 & 2.85 \\
\hline Cumulative contribution rate $(\%)$ & 75.93 & 82.33 & 85.18 \\
\hline
\end{tabular}

Variables with major contributions from each principal component are indicated in bold. BL, body length; HL, head length; ED, eye diameter; PL, post-orbital length; DFL, dorsal fin long-throned length; K, condition factor; HH, head height; HW, head width; SL, snout length; IW, interorbital width; BH, body highness; ML, mouth length; PFL, pectoral fin length; CFL, caudal fin length; PAFD, Distance between pelvic fin and anal fin

The results of R-cluster analysis of 35 morphological parameters by heterocorrelation transformation showed that the standardized relative traits were divided into two branches. The first branch contained $D_{1-2}, \ldots, D_{9-10}$, and $K$, which represented body shape and lean characteristic parameters; and the second branch contained $H L, H H, H W, S L$, $I W, E D$, and $I D L$, which mainly represented the head traits of $H$. maculatus (Fig. 3B). 
(A)

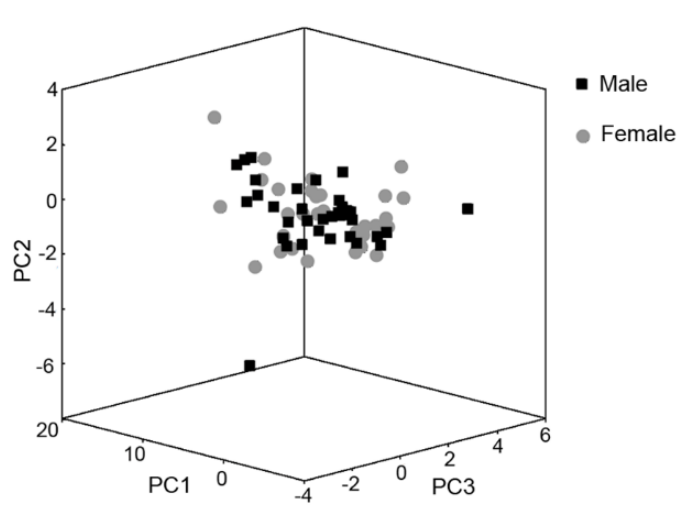

(B)

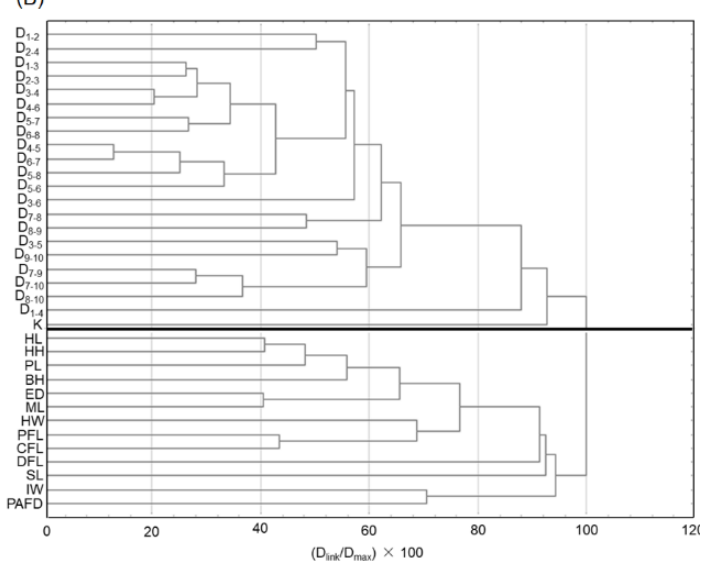

Figure 3. Principal component analysis (PCA) profile based on standardized morphological indexes $(A)$ and R-cluster dendrogram of standardized morphological indexes $(B)$ of $H$. maculatus. BL, body length; $H L$, head length; ED, eye diameter; $P L$, post-orbital length; DFL, dorsal fin long-throned length; $K$, condition factor; $H H$, head height; $H W$, head width; SL, snout length; $I W$, interorbital width; BH, body highness; $M L$, mouth length; $P F L$, pectoral fin length; CFL, caudal fin length; PAFD, Distance between pelvic fin and anal fin

\section{Sex discrimination based on quantitatively morphological characteristics}

The comprehensive discriminant rate based on the traditionally morphological data was $83.82 \%$. (Male: $88.57 \%$; Female: $78.79 \%$ ). The comprehensive discriminant rate based on the truss network data was 91.18\% (Male: 97.14\%; Female: 84.85\%). The comprehensive discriminant rate based on the integrated data of traditionally morphological characteristics and truss network characteristics was $98.53 \%$ (Male: 100\%; Female: 96.97\%). The comprehensive discriminant rates based on the three data transfer methods of the integrated data of traditionally morphological characteristics and truss network characteristics was $82.35 \%$ for ratio (Male: $80 \%$; Female: $84.85 \%$ ), 88.24\% for logarithmic ratio (Male: $94.29 \%$; Female: $81.82 \%$ ), and $92.65 \%$ for ALLOM (Male: $1.43 \%$; Female: $93.94 \%$ ), respectively.

The discriminant formulas for male and female of $H$. maculatus were constructed as follows based on the 13 morphological parameters (i.e. $K, D F L, D_{7-9}, I W, D_{3-6}, D_{4-6}, B H$, $H L, D_{8-9}, D_{6-8}, D_{3-4}, D_{5-8}$, and $D_{3-5}$ ) after the logarithmic heterocorrelation transformation that were screened by stepwise regression,

$$
\begin{aligned}
Y_{1}=-1857.66 & -27.39 \mathrm{~K}-320.14 \mathrm{DFL}+860.03 D_{7-9} \\
& -385.12 \mathrm{IW}+235.83 D_{3-6}-436.43 D_{4-6} \\
& -21.39 B \mathrm{~B}+3527.74 \mathrm{HL}+582.19 D_{8-9} \\
& -1391.47 D_{6-8}+1491.79 D_{3-4}+717.05 D_{5-8} \\
& -232.48 D_{3-5} \\
& \\
Y_{2}=-1960.26 & -33.16 \mathrm{~K}-355.13 D F L+904.87 D_{7-9} \\
& -350.58 I W+258.83 D_{3-6}-474.59 D_{4-6} \\
& -58.20 B H+3644.81 H L+603.11 D_{8-9} \\
& -1446.06 D_{6-8}+1538.12 D_{3-4}+757.36 D_{5-8} \\
& -246.62 D_{3-5}
\end{aligned}
$$


If $Y_{1}>Y_{2}$, the fish was male, otherwise it was female. The significance test of the discriminant function shows that the discriminant function has reached the extremely significant level $\left(F_{(13,54)}=9.2441, P<0.001\right)$. The frequency distribution of each individual's discriminant scores also showed that the model could distinguish male and female H. maculates (Fig. 4). The sixty-eight individuals were judged by the sex discrimination equations (Eq.6 and Eq.7), and anatomical verification, only $5(7.35 \%)$ fish individuals had misjudged sex by the sex discrimination equations. The accuracy rate was $92.65 \%$ (Table 3).

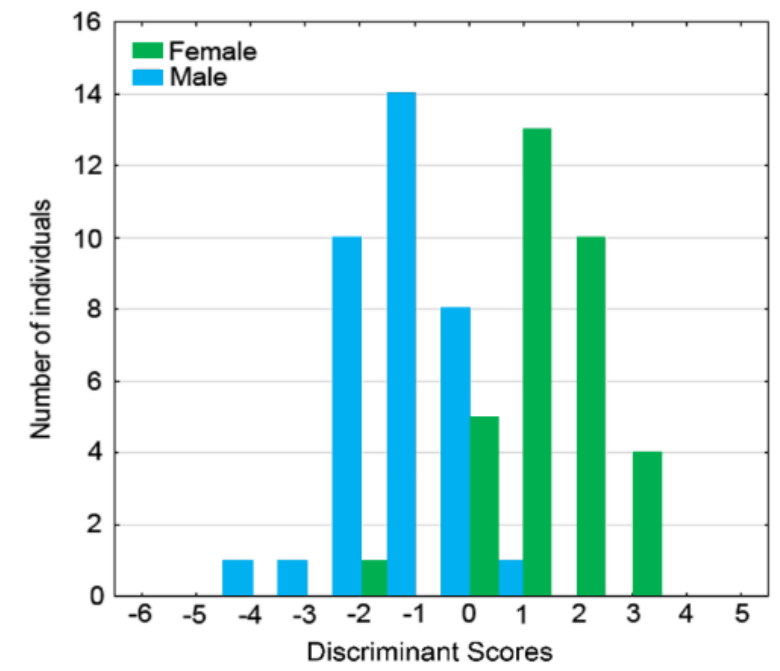

Figure 4. Frequency distribution of discriminant scores of male and female H. maculatus

Table 3. Discriminant analysis results of the stepwise discriminant function analysis based on the standardized morphological data of $H$. maculatus

\begin{tabular}{|c|c|c|c|c|c|c|}
\hline \multirow[b]{2}{*}{ Sex } & \multirow{2}{*}{$\begin{array}{c}\text { Histologic } \\
\text { identification }\end{array}$} & \multicolumn{2}{|c|}{ Predicted result } & \multirow{2}{*}{$\begin{array}{c}\text { Accuracy of } \\
\text { discrimination }(\%)\end{array}$} & \multirow{2}{*}{$\begin{array}{c}\text { Total } \\
\text { discrimination } \\
\text { accuracy }(\%)\end{array}$} & \multirow{2}{*}{ Transformations ${ }^{*}$} \\
\hline & & Male & Female & & & \\
\hline $\begin{array}{l}\text { Male } \\
\text { Female }\end{array}$ & $\begin{array}{l}35 \\
33 \\
\end{array}$ & $\begin{array}{c}28 \\
5\end{array}$ & $\begin{array}{c}7 \\
28 \\
\end{array}$ & $\begin{array}{c}80 \\
84.85\end{array}$ & 82.35 & $M / S L$ \\
\hline $\begin{array}{l}\text { Male } \\
\text { Female }\end{array}$ & $\begin{array}{l}35 \\
33\end{array}$ & $\begin{array}{c}33 \\
6\end{array}$ & $\begin{array}{c}2 \\
27\end{array}$ & $\begin{array}{l}94.29 \\
81.82\end{array}$ & 88.24 & $\log M / \log S L$ \\
\hline $\begin{array}{l}\text { Male } \\
\text { Female }\end{array}$ & $\begin{array}{l}35 \\
33\end{array}$ & $\begin{array}{c}32 \\
2\end{array}$ & $\begin{array}{c}3 \\
31\end{array}$ & $\begin{array}{l}91.43 \\
93.94\end{array}$ & 92.65 & $\begin{array}{c}\log M-b(\log S L- \\
\left.\log S L_{\text {mean }}\right)\end{array}$ \\
\hline
\end{tabular}

${ }^{*} \mathrm{M}$ is the local characteristic measurements of each specimen, SL is the body length of each specimen, $\mathrm{SL}_{\text {mean }}$ is the mean body length of male or female fish, and b is the slope of linear regression of $\log _{10} \mathrm{M}$ and $\log _{10} \mathrm{SL}$

\section{Discussion}

Sexual heteromorphism of individuals is generally interpreted as the result of a combination of sexual selection, fertility selection, and ecological selection (Emlen and Oring, 1977; Lande, 1980; Hedrick and Temeles, 1989). There are three main types of sexual heteromorphism of fish individual size, i.e. female adult is larger than male adult, female adult is smaller than male adult, and the size of male and female individuals is similar (Parker, 1992; Pyron, 1996; Erlandsson and Ribbink, 1997). Lin et al. (2005) 
report that the individual size of $H$. maculatus in the Oujiang River is no significant difference between male and female individuals, while female adults of $H$. maculatus in the Yuanhe River are significantly larger than male adults. This result indicates that the ecological factors from different habitats could influence the heteromorphism of individual size of $H$. maculatus. The difference of local morphological characteristics between males and females showed that the male of $H$. maculatus in the Yuanhe River had larger tail stalk than female, in consistent with eleotrid goby (Odontobutis obscurus) (Fan et al., 2009), and catfish (Clarias fuscus) (Fan et al., 2014).

The results of PCA and R-cluster analysis showed that the morphologic differences of male and female $H$. maculatus in the Yuanhe River mainly concentrated in three aspects: fish body shape, $K$, and head shape, which was basically consistent with the results of I. Elongata (Ni and Chen, 2003) and S. argus (Wu et al., 2014).

Integration of the traditionally morphological indicators and the truss network data could significantly improve the accuracy of sex discrimination of $H$. maculatus, which was consistent with the reports of blunt snout bream (Megalobrama amblycephala) (Li et al., 1991). The ALLOM data transformation method has the highest accuracy for male and female discrimination of $H$. maculatus in Yuanhe River, with a comprehensive recognition rate of $92.65 \%$. It should be further verified whether the transformation method could improve the accuracy in other fish.

\section{Conclusion}

In conclusion, a quantitatively morphological discriminant model for identifying male and female $H$. maculates was established in the present study. The accuracy rate of $H$. maculates discrimination between male and female was $92.65 \%$ using logarithmic heterocorrelation method to transform the quantitatively morphological data. However, automatic identification system based on the model needs to further develop to speed up the identification of male and female $H$. machlates. The best sex ration for artificial propagation of $H$. machlates also needs to further study.

Acknowledgements. The authors thank anonymous technicians at Guangdong Meilikang Bio-Science Ltd., China for assistance with data re-analysis and figure preparation.

\section{REFERENCES}

[1] An, L., Meng, Q., Zhang, L., Dong, X., Li, X., Li, W., Zhu, S. (2017): Analysis of morphological indexes and discrimination of male and female Eryghroculter ilishaeformis. - Freshwater Fisheries 47(2): 36-41.

[2] Bookstein, F. L. (1997): Morphometric tools for landmark data: geometry and biology Cambridge. - New York: Cambridge University Press.

[3] Chang, C.-H., Shao, Y. T., Fu, W.-C., Anraku, K., Lin, Y.-S., Yan, H. Y. (2015): Differentiation of visual spectra and nuptial colorations of two Paratanakia himantegus subspecies (Cyprinoidea: Acheilognathidae) in response to the distinct photic conditions of their habitats. - Zoological Studies 54: 43.

[4] Chen, S., Zhao, R., Qi, D., Fan, X., Lei, H., Lin, Z. (2013a): Sexual dimorphism in morphological traits and female individual fecundity of Acanthorhodeus chankaensis Dybowsky. - Journal of Shanghai Jiaotong University (Agricultural Science) 31(5): 61-66, 78. 
[5] Chen, S., Zhao, R., Zhang, Y., Fan, X., Ding, G., Lin, Z. (2013b): Sexual dimorphism in morphology and female fecundity of Erythroculter ilishaeformis from rivers in Yuyao. Journal of Lishui University 35(2): 11-15.

[6] Corti, M., Thorpe, R. S., Sola, L., Sbordoni, V., Cataudella, S. (1988): Multivariate morphometrics in aquaculture: a case study of six stocks of the common carp (Cyprinnus carpio) from Italy. - Canadian Journal of Fisheries and Aquatic Sciences 45: 1548-1554.

[7] Emlen, S. T., Oring, L. W. (1977): Ecology, sexual selection, and the evolution of mating system. - Science 197: 215-223.

[8] Erlandsson, A., Ribbink, A. J. (1997): Patterns of sexual size dimorphism in African cichlid fishes. - South African Journal of Science 93(11-12): 498-508.

[9] Fan, X., Lin, Z., Lu, J., Qiu, Y., Chen, C., Cao, Y., Qi, D. (2009): Sexual dimorphism in morphological traits and female individual fecundity of Odontobutis obscurus. - Journal of Shanghai Jiaotong University (Agricultural Science) 28(6): 587-591,623.

[10] Fan, X., Lin, Z., Ding, X., Zhu, J. (2014): Sexual size dimorphism and female individual fecundity of Silurus asotus and Clarias fuscus. - Acta Ecologica Sinica 34(3): 555-563.

[11] Fish Research Laboratory of Hubei Institute of Hydrobiology. (1976): Yangtze River fishes. - Beijing: Science Press, 79-80.

[12] Fu, L., Qiao, D. (2008): Studies on the morphology and biology of Hemibarbus maculatus. - Reservoir Fisheries 28(1): 53-55.

[13] Gibbons, J. W., Lovich, J. E. (1990): Sexual dimorphism in turtles with emphasis on the slider turtle (Trachemys scripta). - Herpetological Monographs 4: 1-29.

[14] Guo, H., Wei, K., Xie, Z., Tang, W., Shen, L., Gu, S., Wu, J., Chen, W. (2011): Analysis of morphological index system and discrimination of male and female silver eels (Anguilla japonica) collected at the Yangtze River Estuary. - Journal of Fisheries of China 35(1): 19.

[15] Hedrick, A. V., Temeles, E. J. (1989): The evolution of sexual dimorphism in animals: hypotheses and tests. - Trends in Ecology \& Evolution 4: 136-138.

[16] Lande, R. (1980): Sexual dimorphism, sexual selection, and adaptation in polygenic characters. - Evolution 34: 292-305.

[17] Li, S., Cai, W., Zhou, B. (1991): Morphological and biochemical genetic variations among populations of blunt snout bream (Megalobrama amblycephala). - Journal of Fisheries of China 15(3): 204-211.

[18] Li, P., Xu, D., Peng, Z., Zhang, Y. (2012): The complete mitochondrial genome of the spotted steed, Hemibarbus maculatus (Teleostei, Cypriniformes). - Mitochondrial DNA 23(1): 34-36.

[19] Lin, Z., Lei, H., Lin, Z., Hua, H. (2005): Sexual dimorphism and female reproductive output of Hemibarbus maculates. - Journal of Shanghai Jiaotong University (Agricultural Science) 23(3): 284-288.

[20] Lombardi-Carlson, L. A., Andrews, A. H. (2015): Age estimation and lead-radium dating of golden tilefish, Lopholatilus chamaeleonticeps. - Environmental Biology of Fishes 98(7): 1787-1801.

[21] Miao, X., Yin, M. (1983): A study on the biology of spotted-carp (Hemibarbus maculatus Bleeker) in Tai Hu. - Journal of Fisheries of China 7(1): 31-44.

[22] Ni, H., Chen, X. (2003): Analysis of shape index system and discriminant of male and female of Ilisha elongata. - Journal of Biomathematics 18(2): 224-228.

[23] Parker, G. A. (1992): The evolution of sexual size dimorphism in fish. - Journal of Fish Biology 41 (supplement): 1-20.

[24] Pinheiro, A., Teixeira, C. M., Rego, A. L., Marques, J. F., Cabral, H. N. (2005): Genetic and morphological variation of Solea lascaris (Risso, 1810) along the Portuguese coast. Fisheries Research 73(1-2): 67-78.

[25] Pyron, M. (1996): Sexual size dimorphism and phylogeny in North American minnows. Biological Journal of the Linnean Society 57: 327-341. 
[26] Shou, L., Du, W. G., Shu, L. (2005): Sexual dimorphism and fecundity in the gold-stripe pond frog (Pelophylax plancyi) and the terrestrial frog (Fejervarya limnocharis). - Acta Ecologica Sinica 25(4): 664-668.

[27] Strauss, R. E., Bookstein, F. L. (1982): The truss: body form reconstruction in morphometrics. - Systematic Zoology 31(2): 113-135.

[28] Sun, L., Liu, J., Yang, Y. (2014): Primarily study on fish community structure of Hemibarbus maculatus in Tonglu area of the Qiantang River. - Journal of Biology 31(6): 46-50.

[29] Tuo, Y. (2012): Population characteristics of Hemibarbus maculates in Yuanhe River. Journal of Hydroecology 33(6): 109-113.

[30] Tuo, Y. (2013): Fecundity of Hemibarbus maculates in the Yuanhe River of Jiangxi, China. - Sichuan Journal of Zoology 32(3): 375-379.

[31] Turan, C. (1999): A note on the examination of morphometric differentiation among fish populations: the truss system. - Turkish Journal of Zoology 23(3): 259-263.

[32] Turan, C., Ergüden, D., Gürlek, M., Basusta, N., Turan, F. (2004): Morphometric structuring of the anchovy (Engraulis encrasicolus L.) in the Black, Aegean and northeastern Mediterranean seas. - Turkish Journal of Veterinary and Animal Sciences 28: 865-871.

[33] Wu, X., Yang, Q., Yue, P., Huang, H. (1979): Economic Animals in China - Freshwater Fish. - Beijing: Science Press, 86-87.

[34] Wu, B., Zhang, M., Deng, S., Shi, S., Li, G., Zhu, C. (2014): Analysis of morphological index and discrimination of male and female Scatophagus argus. - Journal of Shanghai Ocean University 23(1): 64-69.

[35] Xie, C., Gong, S., Yang, Z., Zhang, Q. (1988): The growth of Hemibarbus maculatus Bleeker in Nanhu Lake, Wuchang. - Oceanologia et Limnologia Sinica 19(3): 225-231.

[36] Xu, D., Lin, Z., Lei, H. (2006): Sexual dimorphism in morphological traits and female individual fecundity of Acrossocheilus wenchowensis. - Journal of Shanghai Jiaotong University (Agricultural Science) 24(4): 335-340. 


\section{APPENDIX}
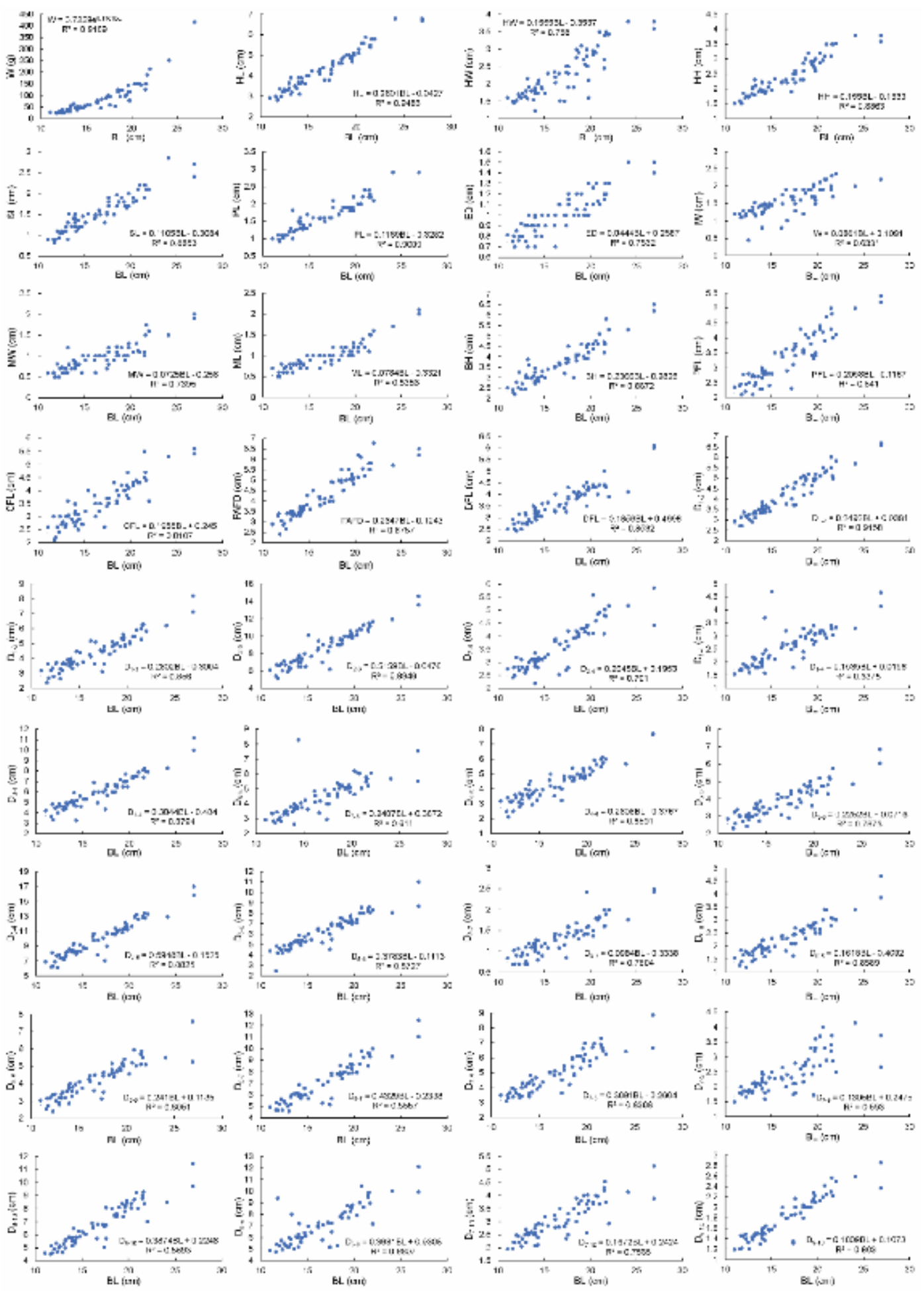

Appendix 1. Correlation between body length (BL) and other morphological parameters. $B L$, body length; HL, head length; ED, eye diameter; PL, post-orbital length; DFL, dorsal fin longthroned length; $K$, condition factor; HH, head height; HW, head width; SL, snout length; IW, interorbital width; BH, body highness; $M L$, mouth length; $P F L$, pectoral fin length; $C F L$, caudal fin length; PAFD, Distance between pelvic fin and anal fin 